\title{
The Effect of Tobacco Smoking on Gingival Crevicular Fluid Volume
}

Kemal Üstün ${ }^{a}, \mathrm{DDS}, \mathrm{PhD}$

Nilgün Ö. Alptekin , DDS, PhD

\begin{abstract}
Objectives: The negative effects of smoking on periodontal health are well known. But the mechanism is not clear yet. The aim of the present study is to investigate the effects of smoking on gingival crevicular fluid (GCF) volume.

Methods: The study included 26 age and gender matched periodontally healthy males. Half of the participants were smokers and the others were non-smokers. After periodontal measures were taken GCF samples were collected from 4 teeth of the subjects. The GCF volume was measured with an electronical device.

Results: The mean plaque index (PI) and gingival crevicular fluid (GCF) volumes were significantly lower in non-smokers $(P=.019$ and $P=.027$, respectively). The other parameters did not show significant differences.

Conclusions: Smoking significantly increased GCF volume compared to non-smoking subjects. This may contribute to the negative effects of smoking on periodontal tissues. (Eur J Dent 2007;1:236239)
\end{abstract}

Key Words: Tobacco smoking; Gingival crevicular fluid; Periodontal risk factor; Plaque index; Periodontal health.

\section{INTRODUCTION}

Smoking is accepted as a risk factor for periodontal disease. ${ }^{1}$ Investigations regarding the association between smoking and periodontal disease have consistently demonstrated negative periodontal effects and greater probabilities of established periodontal disease among smokers in comparison with non smokers. ${ }^{2}$ Subjects who smoke cigarettes have a greater risk of exhibiting more extensive and more severe alveolar bone

a Oral and Dental Health Center, Selçuklu, Konya, Turkey

b Selcuk University, Faculty of Dentistry, Department of Periodontology, Konya, Turkey

Corresponding Author: Kemal Üstün Selçuklu Ā̄ız ve Diș Saḡlıḡı Merkezi Konya, TURKEY e-mail : k_ustundayahoo.com loss. ${ }^{3}$ Smokers tend to have greater numbers of deeper periodontal pockets and mean probing pocket depth. ${ }^{4}$ Several clinical and epidemiological studies indicate that cigarette smoking has harmful effects on the response to a variety of non-surgical ${ }^{5}$ and surgical procedures including: modified Widman flap surgery, ${ }^{6}$ guided tissue regeneration, ${ }^{7}$ dental implants, ${ }^{8}$ and supportive periodontaltreatment. ${ }^{9}$ Smoking also detrimentally affects the neutrophils and macrophages, which are important as gingival immunocompetent cells. Especially, smoking impairs neutrophils chemotaxis and/or phagocytosis. ${ }^{10}$

At comparable plaque levels smokers will not express gingivitis symptoms as clearly as nonsmokers. This was first observed by Bergström 
and Floderus-Myrhed ${ }^{11}$ using a population of Swedish twins, and controlling for plaque index. High exposed twins exhibited a significantly less gingival bleeding propensity as compared to low exposed or unexposed twin partners. A number of later studies have confirmed this finding, ${ }^{12,13}$ suggesting that the gingivitis expression in response to dental plaque is modified by smoking. The effect of smoking on the clinical gingivitis response is a function of the amount of challenge as well as smoking exposure. Under normal conditions of gingival health or with low levels of gingivitis there will be no detectable differences between smokers and nonsmokers. At increased or high levels of plaque challenge the gingivitis reaction of smokers will be comparably suppressed and the more so the greater the challenge and the smoking exposure. Smokers therefore, seldom will show highly increased gingivitis levels, not even in the presence of severe disease. ${ }^{11,12}$

The mechanism through which smoking tobacco deleteriously affects the periodontium remain somewhat obscure although several possibilities have been described. Both locally and systemically induced effects on the periodontium have been described. Smoking tends to mask gingival inflammation ${ }^{11,12}$ by causing constriction of the blood vessels of the gingiva, as well as the coronary arteries. ${ }^{14}$

Gingival crevicularfluid (GCF) isan inflammatory exudate. Its presence in clinically normal sulci can be explained by the fact that gingiva that appears clinically normal invariably exhibits inflammation when examined microscopically. ${ }^{15}$ The amount of gingival fluid is greater when inflammation is present and is sometimes proportional to the severity of the inflammation. ${ }^{16}$ Gingival fluid production is increased by mastication of course foods, tooth brushing, gingival massage, ovulation, hormonal contraceptives, and smoking. ${ }^{17}$ GCF volume is a well known marker of gingival health and have been used in many studies. ${ }^{18}$ Smoking was reported to produce an immediate transient but marked increase in gingival fluid flow but the cumulative effect of smoking in GCF have not been examined.

The aim of the present study was to evaluate the influence of tobacco smoking on clinical parameters and GCF volume.

\section{MATERIALS AND METHODS}

All volunteers who participated in the study provided written informed consent. Subjects were recruited from patients newly referred to the Selcuk University Faculty of Dentistry Department of Periodontology. The study population included age matched 13 males. Their mean age was 40.8 years (range $35-50$ ). The patients did not have any teeth with probing depth (PD) $\leq 3 \mathrm{~mm}$ and clinical attachment loss (CAL). Subjects with potential confounding factors such as diseases of oral hard or soft tissues except caries and periodontal disease, a history of diabetes, hepatitis, or HIV infection, in need for premedication for dental treatment, chronic usage of anti-inflammatory drugs, immunosuppressive chemotherapy, history of any disease known to severely compromised immune function, current acute necrotizing ulcerative gingivitis, or use of orthodontic appliances. The study included both smokers and nonsmokers where smoking status was classified based on cigarette consumption calculated in pack years. ${ }^{19}$ Subjects were selected on the basis of reported smoking habits, namely, smokers who claimed to have smoked at least 1 pack (20 cigarettes) for the past 5 years at the minimum. Non-smokers were defined as people who had never smoked. The study was approved by Local Ethic Committee at Selcuk University, Faculty of Dentistry (2004-132), and written informed consent was obtained from all participants before inclusion in the study in accordance with the Helsinki declaration.

\section{Clinical recordings}

Prior to crevicular fluid collection, supra gingival plaque was scored using plaque index (PI). ${ }^{20}$ Gingival inflammation was scored following crevicular fluid collection using gingival index (GI). ${ }^{21}$ Full mouth PD and CAL measures were obtained at six points (mesial, distal and midpoints) of all teeth using a conventional periodontal probe. All clinical data were recorded by one examiner (KU).

\section{Crevicular fluid sampling}

For GCF sampling \#16,21,36,41 teeth were chosen. If one of them is missing the nearest tooth was used for sampling. After supragingival plaque was removed from each tooth, the individual tooth site was gently air dried and isolated with cotton rolls. Each GCF was collected with paper strips 
(Periopaper, Proflow Inc.,Amityville, NY). The paper strip was inserted into the crevice at the mesial part of the tooth until mild resistance was felt. Strips which were contaminated with saliva or blood were discarded. The strips were left in situ 30 s and then transferred for volume determination with an electronic device (Periotron 8000, Oraflow Inc.,Plainview, NY). The readings were converted to actual volume $(\mu \mathrm{l})$ by reference to the standard curve.

\section{Statistical analysis}

Data were expressed as means and standard deviations. The statistical significance of differences between groups was tested according to non parametric ANOVA (Mann-Whitney U) test. The null hypothesis was rejected at $P<.05$. For statistical analysis SPSS 13 program was used (SPSS Inc., Chicago, IL).

\section{RESULTS}

Age and gender matched 13 smokers, and 13 non-smokers were recruited for this study. All the participants were males. Table 1 shows the periodontal status of each group, including $\mathrm{PI}, \mathrm{GI}$, $\mathrm{CAL}, \mathrm{GCF}$ volume $(\mu \mathrm{l})$, and numbers teeth present in the mouth.

The PI scores were significant different between smokers and non-smokers (P=.019). The PI scores were higher in smokers. The $\mathrm{Gl}$ scores were not significantly different between groups $(P=$.109). CAL scores were not significantly different between groups $(P=$.207). The GCF volumes were significant different between smokers and nonsmokers ( $P=$.027). The GCF volumes were higher in smokers.

\section{DISCUSSION}

In this study GCF amounts and PI scores were found higher in smokers than in age and gender matched non-smokers. All the participants were male in this study. It is known that GCF amount are affected by ovulation, hormonal contraceptives. ${ }^{17}$ By selecting male subjects this possible affect is eliminated. Previous studies reported gingiva of older subjects responded earlier and in a more pronounced manner to plaque accumulation than younger subjects. ${ }^{22}$ Therefore, discrimination of subjects in relation to plaque and smoking could be affected by the age of examined subjects. In the present study an age-gender matched design is preferred. The reason for this design is to effectively eliminate any age and gender dependent inter individual susceptibility differences.

Also, an increase of GCF volume due to the effect of cigarette smoking has been demonstrated by McLaughlin et $\mathrm{al}^{23}$. In a recent study blood flow of gingiva was measured with a laser Doppler and found an increase in the gingival blood flow rate. Authors mentioned that normally smoking causes a vasoconstriction. How ever, the degree of vasoconstriction was far less than in the thumb skin, and overcome by the evoked rise in arterial perfusion pressure. As a consequence, gingival blood flow increased during smoking. It is speculated that small repeated vasoconstrictive attacks due to cigarette smoking may in the long run contribute to gingival vascular dysfunction and periodontal disease. ${ }^{24}$ On the other hand lower GCF volumes have been reported. ${ }^{25}$ The lower GCF volumes were linked with diminished gingival blood flow in smokers.

Table 1. Summary statistics for Plaque Index (PI), Clinical Attachment Level (CAL), Gingival Index (GI), Number of tooth present in the mouth, Gingival Crevicular Fluid (GCF) volume in the study population (mean \pm SD).

\begin{tabular}{lccccc}
\hline \multicolumn{5}{c}{ Smoking } & \multicolumn{5}{c}{ Non-Smoking } \\
\hline & Mean & SD & Mean & SD & P Value \\
\hline PI & 1.71 & 0.68 & 1.15 & 0.33 & 0.019 \\
GI & 1.44 & 0.53 & 1.14 & 0.27 & 0.109 \\
CAL & 2.30 & 0.48 & 2.30 & 0.20 & 0.207 \\
GCF $(\mu \mathrm{l})$ & 0.40 & 0.23 & 0.23 & 0.14 & 0.027 \\
\hline Teeth Present & 25.90 & 1.90 & 26.30 & 1.70 & 0.600 \\
\hline
\end{tabular}


The most important limitation of this study is the small sample size and high PI levels of smoking group. Higher plaque indexes expected to effect $\mathrm{GI}$ and GCF volume. Although higher PI the GI of the groups were not statistically different. This result confirms that smoking decreases signs of $\mathrm{GI}$.

\section{CONCLUSIONS}

The results of this study showed that GCFvolume was higher in smokers than in non smokers. GCF volume is known to increase with the degree of inflammation. Although GI was similar that of nonsmokers, the increased volume of GCF shows the presence of a masked inflammation in smokers. The components of the GCF must be examined for better understanding the progression of disease.

\section{REFERENCES}

1. Page RC, Beck JD. Risk assessment for periodontal diseases. Int Dent $J$ 1997;47:61-87.

2. Ojima M, Hanioka T, Tanaka K, Inoshita E, Aoyama H. Relation ship between smoking status and periodontal conditions: Findings from national databases in Japan. $J$ Periodont Res 2006;41:573-579.

3. Bergstrom J, Eliasson S. Cigarette smoking and alveolar bone height in subjects with a high standard of oral hygiene. J Clin Periodontol 1987;14:466-469.

4. Haber J, Wattles J, Crowley M, Mandell R, Joshipura K, Kent RL. Evidence for cigarette smoking as a major risk factor for periodontitis. J Periodontol 1993;64:16-23.

5. Preber H, Bergström J. The effect of non-surgical treatment on periodontal pockets in smokers and non smokers. J Clin Periodontol 1985;13:319-323.

6. Preber H, Bergström J. The effect of cigarette smoking on periodontal healing following surgical periodontal therapy. J Clin Periodontol 1990;17:324-328.

7. Tonetti MS, Pini-Prato G, Cortellini P. Effect of cigarette smoking on periodontal healing following GTR in infrabony defects. A preliminary retrospective study. JClin Periodontol 1995;22:229-234.

8. Lambert PM, Morris HF, Ochi S. The influence of smoking on 3 year clinical success of osseointegrated implants. Ann Periodontol 2000;5:79-89.

9. Kaldahl WB, Johnson GK, Patil KD, Kalkwarf KL. Levels of cigarette consumption and response to periodontal therapy. J Periodontol 1996;67:675-681.

10. Eichel B, Shahrik HA. Tobacco smoke toxicity: loss of human oral leukocyte function and fluid cell mechanism. Science 1969;166:1424-1428.

11. Bergström J, Floderus-Myrhed B. Co-twin control study of the relationship between smoking and some periodontal disease factors. Community Dent Oral Epidemiol 1983;11:113116.

12. Bergström J. Oral hygiene compliance and gingivitis expression in cigarette smokers. Scand $J$ Dent Res 1990;98:497-503.

13. Danielson B, Manji F, Nagelkerke N, Fejerskov O, Baelum V. Effect of cigarette smoking on the transition dynamics in experimental gingivitis. J Clin Periodontol 1990;17:159-164.

14. Baab DA, Oberg PA, The effect of cigarette smoking on gingival blood flow in humans. $J$ Clin Periodontol 1987; 14:418-424.

15. Page RC. Host response tests for diagnosing periodontal diseases. J Periodontol 1992;63:356-366.

16. Shapiro L, Goldman H, Bloom A. Sulcular exudates flow in gingival inflammation. J Periodontol 1979;50:301.

17. Nisengaard RC, Newman MG, Sanz M, Host response: Basic Concepts in: Carranza FA, Newman MG. Clinical Periodontology WB Saunders Company London.

18. Persson L, Bergström J, Gustafson A, Asman B. Tobacco smoking and gingival neutrophil activity in young adults. $J$ Clin Periodontol 1999;26:9-13.

19. Bernaards CM, Twisk JWR, Snel J, Mechelen WV, Kemper HCG. Is calculating pack years retrospectively a valid method to estimate life time tobacco smoking: a comparison between prospectively calculated pack years and retrospectively calculated pack years. Addiction 2001;96:1653-1662.

20. Silness P, Löe H. Periodontal disease in pergnancy. Acta Odontol Scand 1964;22:121.

21. Löe H, Silness J. Periodontal disease in pregnancy. Acta Odontol Scand 1963;21:533.

22. Fransson C, Berglund T, Lindhe J. The effect of age on the development of gingivitis. Clinical,microbiological and histological findings. J Clin Periodontol 1996;23:379-385.

23. McLaughlin WS, Lovat FM, Macgregor IDM, Kelly PJ. The immediate effects of smoking on gingival fluid flow. $J$ Clin Periodontol 1993;20:448-451.

24. Mavropulos A, Aars H, Brodin P. Hyperamic response to cigarette smoking in healthy gingiva. $J$ Clin Periodontol 2003;30:214-221.

25. Morozumi T, Kubota T, Sato T, Okuda K, Yoshie H. Smoking cessation increases gingival blood flow and gingival crevicular fluid. J Clin Periodontol 2004;31:267-272. 